\title{
Analysis of potential low frequency resonance between a 1GW MMC HVDC and a nearby nuclear generator
}

\author{
Stefan Kovacevic*a, Dragan Jovcic ${ }^{\mathrm{a}}$, Sumeet S. Aphale ${ }^{\mathrm{a}}$, Pierre Rault ${ }^{\mathrm{b}}$, Olivier Despouys ${ }^{\mathrm{b}}$ \\ ${ }^{\text {a }}$ School of Engineering, University of Aberdeen, Aberdeen, Scotland, UK, AB24 3 UE. \\ e-mails: *corresponding author r02sk17@abdn.ac.uk,d.jovcic@abdn.ac.uk, s.aphale@abdn.ac.uk \\ ${ }^{\text {b }}$ Réseau de Transport d'Électricité, Paris, France (funding body of the corresponding author's PhD project). \\ e-mails: pierre.rault@rte-france.com, olivier.despouys@rte-france.com
}

\section{Abstract}

This paper presents a comprehensive analytical eigenvalue stability study of subsynchronous torsional interactions between the 1GW Eleclink MMC HVDC and the 1.12GW Gravelines turbine-generator in north France. It shows that when the generator and HVDC have similar power rating and the generator has low frequency torsional mode, the level of adverse interactions can be of significance. The worst case-scenario is when the generator and HVDC deliver rated power from the French to the English grid and the French grid is weak, and in extreme the HVDC could even destabilize the dominant $6.3 \mathrm{~Hz}$ mode. The results also show a noticeable effect of PLL, namely, increasing the gains can improve the stability margins. Participation factors are also analyzed for the $6.3 \mathrm{~Hz}$ mode indicating that the main cause of the torsional interactions is the HVDC power control loop. The scenario of the HVDC importing power from the English grid shows that the HVDC could deteriorate damping of the $6.3 \mathrm{~Hz}$ mode but only for high AC voltage controller gains. Reducing PLL gains in this case improves the damping which also suggests adopting different PLL gains on the rectifier and the inverter. The main findings are verified on the detailed EMTP model. 


\section{Keywords}

Eigenvalue analysis, small-signal state-space modelling, SSTI, MMC HVDC, synchronous generator, PLL.

\section{Introduction}

Subsynchronous resonance (SSR) is a well-known and well documented phenomenon [1][2][3]. It represents a condition where the electrical network exchanges significant energy with the mechanical shaft of a turbine-generator. It occurs when the generator with poorly damped torsional mode of the mechanical shaft is connected to the electrical system which has a negative damping contribution at the frequency of the torsional mode. This interaction can cause growing rotor speed oscillations and lead to permanent damage of the generator shaft and may cause severe stability problems on the power grid. This is the reason why the SSR has been the topic of an extensive research, over the course of many years. The risk of SSR was first detected in generators connected to series compensated AC transmission systems, namely the failure of a turbine-generator shaft at the Mohave plant in southern California in 1970 [4]. Since then, a number of studies have led to the in-depth understanding of the mechanism behind the phenomenon [5][6] as well as the development of the benchmark models for the SSR studies [7][8].

The risk of SSR has also been detected in generators connected to high voltage direct current (HVDC) systems. The first case was demonstrated at the Square Butte project in North Dakota in 1977 [9]. The concerned HVDC is based on the traditional line commutated converter (LCC) technology and the subsequent analytical work revealed that the root cause of the issue was the control of the HVDC power transfer [9]. Since this type 
of SSR represents interaction between the control of an HVDC and the mechanical shaft of turbine-generators, it is also commonly referred to as the subsynchronous torsional interactions (SSTI). There have been multiple cases reported on SSTI between LCC HDVC and generators worldwide [9][10] and this topic is well known and well researched $[9][11][12]$. However, there is limited practical experience and published work on SSTI with voltage source converter (VSC) based HVDC systems and it is expected that these systems also introduce the risk of SSTI since they typically control active power transfer. This topic is gaining much interest since the VSC are superseding the LCC technology in recent years. Among VSC technologies, the modular multilevel converter (MMC) is particularly gaining interest as shown by the rapidly increasing number of planned MMC HVDC systems worldwide [13] which raises concerns about the stability issues caused by SSTI.

Most of the studies on SSTI between VSC-based HVDC and generators investigate twolevel VSC topology [14][15][16] [17] which has less complicated internal dynamics compared to MMC. The study in [17] is probably the most relevant one for the two-level VSC because it adequately represents the subsynchronous dynamics of the generator and accounts for the complete control structure of the typical VSC HVDC. The results of this study indicate that a VSC-based HVDC can deteriorate torsional damping of a generator, however, the impact is small and the risk of SSTI is minor in most of the practical systems. The most comprehensive and accurate study of SSTI between MMC HVDC and a turbinegenerator is conducted in [18] and it derives a similar conclusion. However, the study investigates the impact of a $100 \mathrm{MW}$ MMC on a $600 \mathrm{MW}$ generator with the frequency of the first (lowest) torsional mode equal to $15.6 \mathrm{~Hz}$. Based on the experience with the LCC 
HVDC, it is expected that the risk of SSTI would be much higher in case of MMC and generator having similar power rating and the generator having lower frequency torsional modes. Also, this study analyzes only one power flow direction (exporting power from the generator side) and does not analyze the impact of the PLL gains. Furthermore, the study is based on the time-domain simulations of detailed EMT models which means that it cannot investigate the root cause of the torsional interactions. The study in [19] shows that the cause of the adverse subsynchronous oscillations for MMC HVDC in general is the closeness of an open loop control mode to one of the subsynchronous grid modes. However, an in-depth study with respect to the torsional phenomenon is still missing. This paper analyzes SSTI in a realistic test system representing north French HVDC topology operated by RTE, French TSO. The system includes in-development crosschannel 1GW MMC HVDC link Eleclink and Gravelines nuclear 1.12 GW generator. The Gravelines generator lowest torsional mode of concern has a frequency of $6.3 \mathrm{~Hz}$ which has been investigated for SSTI stability concerns with the existing IFA2000 LCC HVDC [10]. The aim is to analyze SSTI by the analytical means using eigenvalue stability assessment which has been successfully employed in the past for various HVDC stability studies $[11][12][20]$. The intension is to conduct a comprehensive study:

- of various AC parameters and operating points,

- HVDC controller gains, including PLL,

- commonly used control modes on HVDC such as AC voltage, reactive power and AC voltage droop control,

- both power flow control directions of the HVDC, 
- participation factors in case of unstable torsional modes.

The main findings will be validated by the means of time-domain simulations on the nonlinear EMTP model. It will be demonstrated that contrary to conclusions in [17] and [18], MMC HVDC may potentially significantly deteriorate SSTI interactions. Furthermore, as the accurate MMC state space model will be employed [22], this will show a different impact of the MMC compared to the two level VSC in [17].

\section{State space modelling and HVDC test system}

This section presents the HVDC test system, corresponding state space model and introduces the linearized dynamic model.

\subsection{HVDC test system}

The test system is depicted in Fig 1. It is composed of a point-to-point MMC HVDC link Eleclink (total length of the link is $70 \mathrm{~km}$ ) connecting French and English AC grid. The MMC station in France is connected to Gravelines nuclear plant generator via $30 \mathrm{~km}$ overhead transmission line.

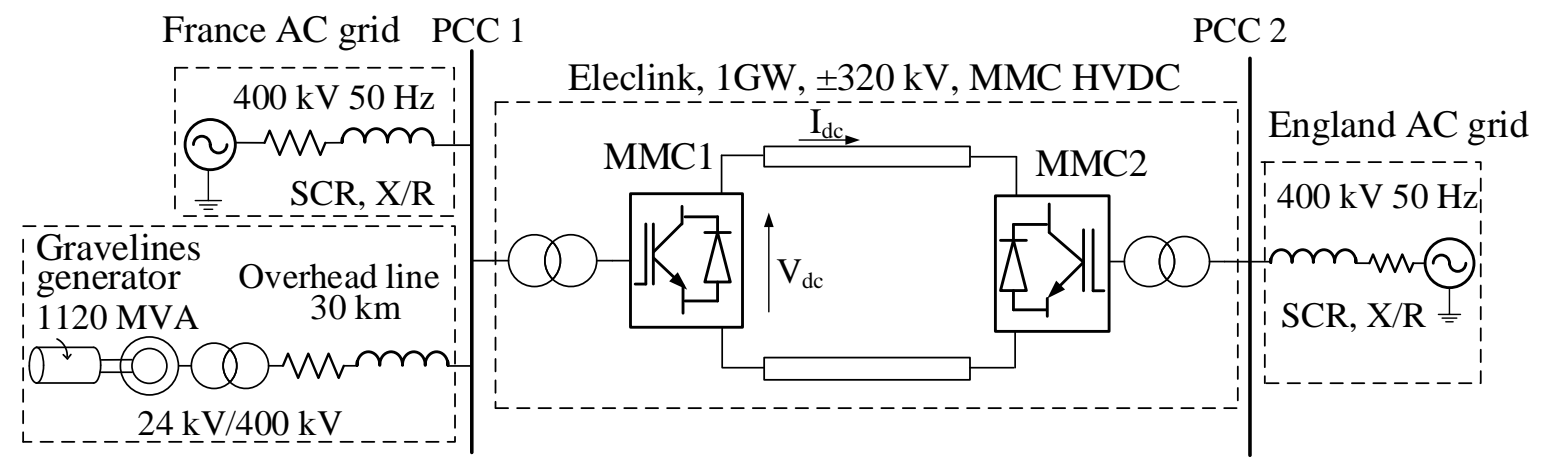

Fig 1. Schematic of the HVDC test system

\subsection{Complete state space model}

The small signal state space model of the complete test system is assembled by 
connecting four state space subsystems: generator, HVDC and two AC grids, as depicted in

Fig 1. This makes the model flexible and facilitates changing topology, e.g. expanding to a dual-infeed HVDC system. The complete model is of the $186^{\text {th }}$ order and it is implemented in MATLAB. The model is verified by comparing small signal responses against the detailed EMTP model for various inputs and conditions. The model structure is presented in Fig 2 along with the corresponding states. The individual elements of the schematic are explained in the following sections.

\begin{tabular}{|c|c|c|c|}
\hline $\begin{array}{l}\text { AC grid France: } \\
2 \text { states (DQ current) }\end{array}$ & & \multicolumn{2}{|c|}{$\begin{array}{l}\text { AC grid England: } \\
2 \text { states (DQ current) }\end{array}$} \\
\hline Generator model: 42 states & \multicolumn{3}{|c|}{ HVDC model: 138 states } \\
\hline \multirow{4}{*}{$\begin{array}{l}4 \text { mass (turbine) mechanical shaft: } 8 \text { states } \\
\text { (turbine angles and speeds) } \\
\text { Rotor and stator electrical } 2.2 \text { model: } 5 \text { states } \\
\text { (Sub transient, transient and stator DQ flux) }\end{array}$} & French MMC & \multirow{7}{*}{$\begin{array}{c}\text { Wideband } \\
\text { frequency } \\
\text { dependent } \\
70 \mathrm{~km} \\
\text { cable } \\
\text { model: } \\
50 \text { states }\end{array}$} & English MMC \\
\hline & \multirow{6}{*}{$\begin{array}{l}\text { Transformer and } \\
\text { AC side: } 4 \text { states } \\
\text { Converter control: } \\
30 \text { states } \\
\text { Converter model: } \\
10 \text { states }\end{array}$} & & \multirow{6}{*}{$\begin{array}{l}\text { Transformer and } \\
\text { AC side: } 4 \text { states } \\
\text { Converter control: } \\
30 \text { states } \\
\text { Converter model: } \\
10 \text { states }\end{array}$} \\
\hline & & & \\
\hline & & & \\
\hline AC4A exciter: 3 states & & & \\
\hline PSS2A power system stabilizer: 16 states & & & \\
\hline IEEEG1 steam turbine governor: 8 states & & & \\
\hline $\begin{array}{l}\text { Transformer (AC side): } 2 \text { states } \\
30 \mathrm{~km} \text { tie line: } 2 \text { states (DQ current) }\end{array}$ & \multicolumn{3}{|c|}{$\begin{array}{l}\text { Converter states: DQ0, DQ and DQ2 max. arm voltage, } \\
\text { DQ0 and DQ2 differential current, } \mathrm{M}_{\mathrm{DO} 2} \text { modulation indices }\end{array}$} \\
\hline
\end{tabular}

Fig 2. Schematic of the small-signal, analytical, DQ state space model.

The state space model incorporates power flow solution of the French and the English grid, and the steady-state solution of the two MMCs. This is used to initialize all the gains of the linearized models. This means that the state space model can be used in stand-alone, without performing power flow and time-domain simulations in EMTP. This facilitates performing AC parameter studies which implies changes of the operating point and the power flow.

In the power flow analysis, the $\mathrm{AC}$ grid is represented as a slack bus (behind an impedance) while MMC can be either a PQ or $\mathrm{PV}_{\mathrm{ac}}$ source depending on the control mode. The generator terminal is a PQ source which enables changing reactive power. Since the 
generator actually controls the terminal AC voltage, the voltage is calculated in the power flow solution to provide the set reactive power.

\subsection{State space model of HVDC}

\subsubsection{HVDC parameters}

There is limited data on the Eleclink HVDC in public domain and therefore some parameters are adopted from the standard EMTP model of the MMC HVDC [21]. All the parameters are provided in Table 3 in Appendix, excluding the controller parameters (this will be defined later). The controller has multiple nested loops and final tuning is achieved considering overall stability, performance, robustness and considering experience from industry with previous projects [21].

\subsubsection{Linearized dynamic MMC model}

The state space model of the MMC HVDC follows the MMC modelling methods verified in [22]. This basic MMC model (with no control) is of the $10^{\text {th }}$ order and in three coordinate frames: DC frame, fundamental frequency frame and double fundamental frequency frame. The model is derived by linearizing the average value model and this neglects the higher frequency switching dynamic. However, it adequately represents the circulating current dynamic and the suppression control (CCSC) which makes the model accurate for the stability assessment of the SSTI as well as the control interactions in a wider frequency domain. This model is much more accurate than the simple two level VSC used in [17], considering that most modern HVDC use MMC technology.

\subsubsection{State space model of the DC cable}

The state space model of the subsea cable is assembled by performing direct vector fitting method on the wideband cable model [23]. This model is of the $50^{\text {th }}$ order, and 
accuracy is verified against the EMTP model in the frequency range up to $1 \mathrm{kHz}$. It is

known that simple DC cable models can not accurately represent interactions with MMC

HVDC [24].

\subsubsection{HVDC control}

The models of the two MMC are connected using the DC cable model to form the HVDC link and the model is completed by developing the control structure. A standard MMC HVDC control is used as depicted in Fig 3. The reactive power controller uses AC voltage droop feedback which is commonly used in HVDC. Table 1 list the considered operating modes. Control mode 1 (including voltage droop from Control mode 5) and Control mode 2 represent normal operation. Control mode 3 and 4 are used on a few

HVDC worldwide and are considered for completeness.

\begin{tabular}{|l|l|l|l|l|}
\hline Control mode & \multicolumn{2}{|c|}{ Rectifier control } & \multicolumn{2}{c|}{ Inverter control } \\
\hline Control mode 1 & Active power & Reactive power & DC voltage & Reactive power \\
\hline Control mode 2 & Active power & AC voltage & DC voltage & AC voltage \\
\hline Control mode 3 & DC voltage & Reactive power & Active power & Reactive power \\
\hline Control mode 4 & DC voltage & AC voltage & Active power & AC voltage \\
\hline Control mode 5 & Active power & AC voltage droop & DC voltage & AC voltage droop \\
\hline
\end{tabular}

Table 1. Control modes of the HVDC

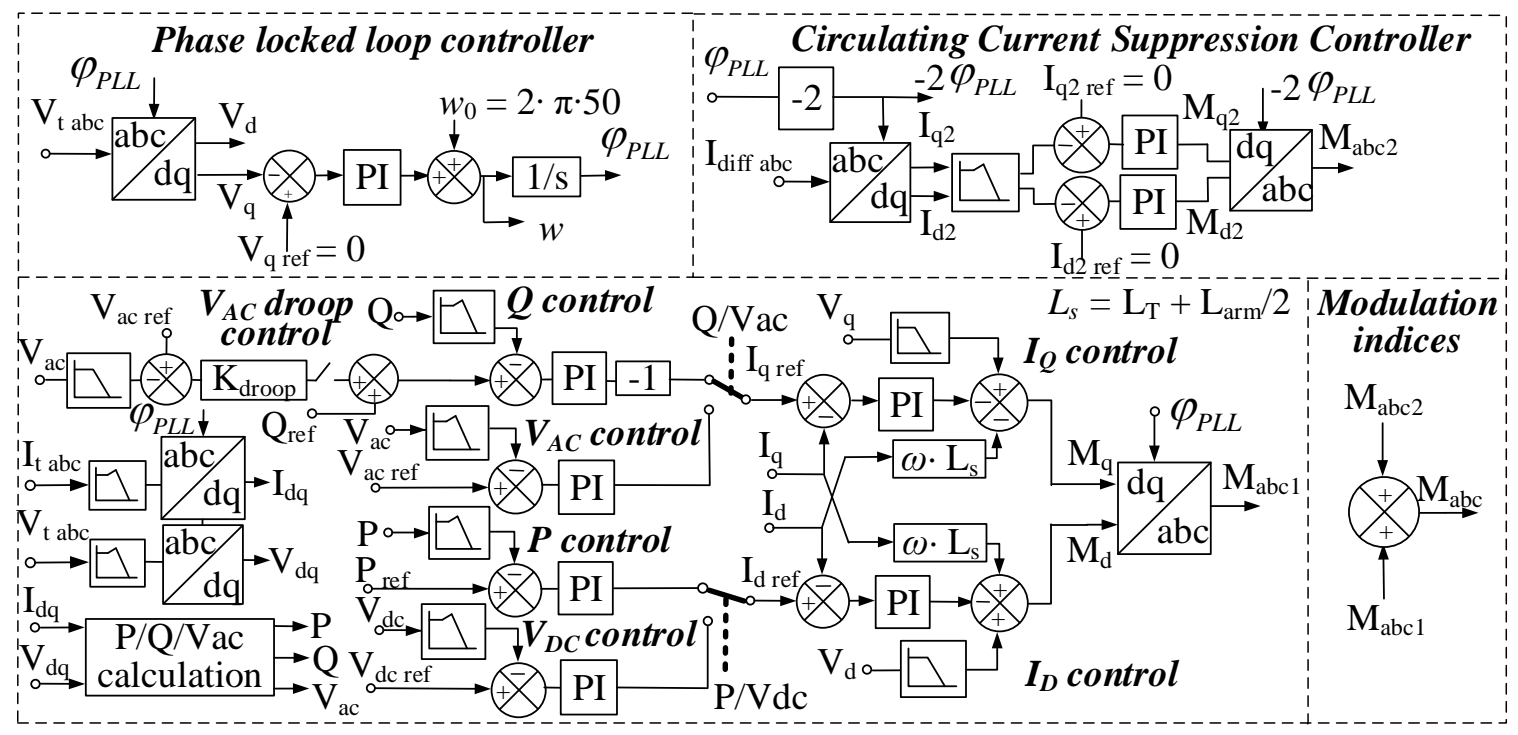

Fig 3. Schematic of the HVDC control 
The PLL is of DQZ type and the model details are given in [28]. Prior to the analysis, a range of feasible controller parameters, including PLL, is defined. This is determined by observing small signal step performance for various inputs and various strengths of the AC grid. The AC grid strength is represented using short circuit ratio (SCR), which is short circuit capacity divided with the HVDC power rating, and X/R. The range of controller gains is determined (with a $\pm 50 \%$ tolerance) to ensure settling time around $0.01 \mathrm{~s}$ for DQ currents and 0.1 s for outer loops, with overshoot below $20 \%$ for the SCR in the 2-10 range on both sides of the HVDC. Only the AC voltage controller integral gain is defined in a wider range to allow maintaining desired settling time for the entire SCR range - stronger AC grids require higher gains. The established range of controller gains is provided in Table 4 in Appendix. The provided basic values are adopted for the initial SSTI assessment. The defined controller range also provides similar performance for large signal disturbances such as the three phase short circuit in the 2-10 SCR range.

\subsection{State space generator model}

\subsubsection{Linearized dynamic generator model}

The model is based on the linearized dynamic generator model in [11], and is presented in [12]. The shaft is represented with a multi-mass model as required for the SSTI studies.

Some Gravelines generator parameters are given in [25], while shaft modes are reported in [10]. The Gravelines shaft parameters are not available in public domain, so, a parameter identification procedure is employed with the aim of adequately representing subsynchronous dynamics, i.e. the shaft torsional modes [12]. The mechanical shaft is represented using four connected masses which accounts for the three torsional modes of 
concern [10]. The selected electrical parameters are provided in Table 5 (in Appendix) which also shows the obtained mechanical parameters.

\subsubsection{Generator control}

According to the IEEE standard for the excitation system models [26], the stationary exciter type AC4A is adopted. Also, the PSS2A power system stabilizer is included which has active power and rotor speed as the inputs. According to the IEEE recommended practice on governor systems [27], the IEEEG1 steam turbine governor is adopted. The parameters of the controllers are adopted from the same standards.

\subsubsection{Torsional modes}

The study in [12] verified the state space generator model by replicating the results of the experimental study on SSTI between Gravelines generator and IFA2000 LCC HVDC [10]. The model correctly identified frequency and damping of the three generator torsional modes: the $6.3 \mathrm{~Hz}$ mode (which is the most critical), the $12 \mathrm{~Hz}$ mode and the $16 \mathrm{~Hz}$ mode (which cannot be excited by the electric grid and is not consider for the SSTI analysis).

\subsection{Operating conditions and $\mathrm{AC}$ parameter range}

The impact of the following AC parameters is analyzed: HVDC loading, generator active/reactive power, SCR and X/R ratio of the French and English AC grid and distance between the HVDC and the generator. The impact of the MMC reactive power is investigated for Control mode 1 and 3 while the impact of the AC voltage at the point of common coupling (PCC) is investigated for Control mode 2 and 4. It is to be noted that the operating conditions are always chosen so that the PCC voltage is within the $380-420 \mathrm{kV}$ range (within $\pm 5 \%$ of the rated value). The SCR of the French grid is expected to decrease 
as low as 3 in some operating conditions [10], however, lower values are also feasible with MMC HVDC [28]. The range of AC parameters considered for the SSTI assessment is provided in Table 6 in Appendix.

\section{Eigenvalue stability assessment}

The SSTI are analyzed by changing key AC parameters, operating points and controller gains and observing damping of Gravelines $6.3 \mathrm{~Hz}$ and $12 \mathrm{~Hz}$ torsional modes (imaginary part of the eigenvalues representing torsional modes changes very little and is not depicted). Torsional damping is then compared to the case of isolated Gravelines generator (when the HVDC is disconnected) to determine the impact of the HVDC.

\subsection{HVDC exporting power from France to England}

\subsubsection{Impact of HVDC loading and French SCR}

The eigenvalue studies show that increasing generator or HVDC loading or reducing French SCR deteriorates torsional damping. This means that the worst-case scenario for SSTI is when generator and HVDC are at rated active power. Fig 4 shows obtained damping of the $6.3 \mathrm{~Hz}$ and $12 \mathrm{~Hz}$ torsional modes for the change of the French SCR. The generator and HVDC are delivering rated power. Generator power factor is 0.95 overexcited. For the HVDC in Control mode 1 and 3, MMC power factor is kept at unity, and for the HVDC in Control mode 2 and 4, PCC voltage is kept at the rated value. The $\mathrm{X} / \mathrm{R}$ ratio is 10 on both sides of the HVDC and SCR of the English AC grid is 5. By comparing the obtained damping to the case of the isolated generator, it can be seen that the HVDC always deteriorates damping of both the $6.3 \mathrm{~Hz}$ and $12 \mathrm{~Hz}$ modes. For very low French SCR, the HVDC can even destabilize the $6.3 \mathrm{~Hz}$ mode - SCR below 1.5 for Control 
mode 2. Even for the realistically low French SCR equal to 3 [10], the adverse impact of the HVDC is notable: damping is reduced by 0.08 for the $6.3 \mathrm{~Hz}$ mode and by 0.07 for the $12 \mathrm{~Hz}$ mode. This applies to the Control mode 2 which has the most detrimental impact. Reactive power control has slightly less negative impact compared to AC voltage control. Also, AC voltage droop control is not much different from the reactive power control (difference is less than 0.01). They also show similar impact in the analysis of the rest of the AC parameters.
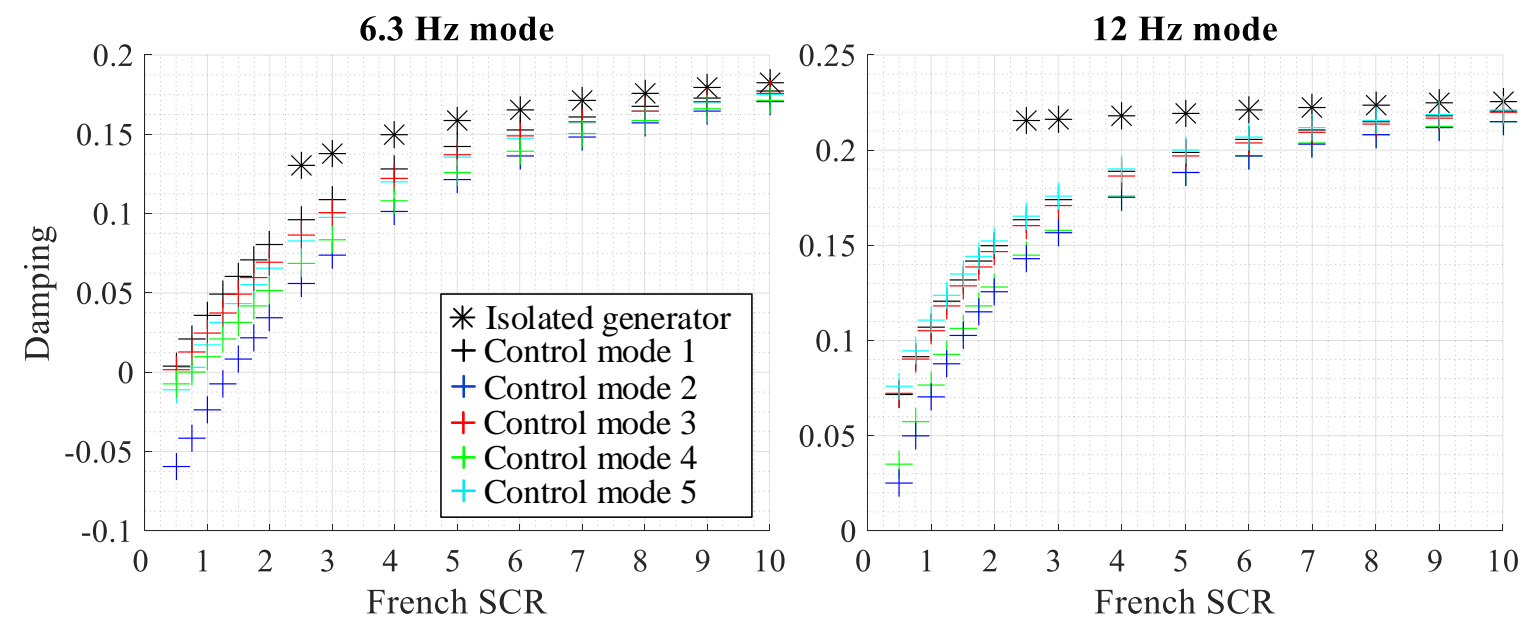

Fig 4. Torsional damping for the change of the French SCR. HVDC and generator are delivering rated power.

The impact of the HVDC loading on the damping of the $6.3 \mathrm{~Hz}$ and $12 \mathrm{~Hz}$ modes is shown in Fig. 5. This is obtained for the French SCR equal to 3 which represents the lowest expected value in the North French system according to [10] . All other operating conditions remain the same. As can be seen, increasing HVDC active power deteriorates torsional damping. The impact of the generator active power is not exhibited because the results agree with the well-known torsional characteristics of generators [1][12]. 


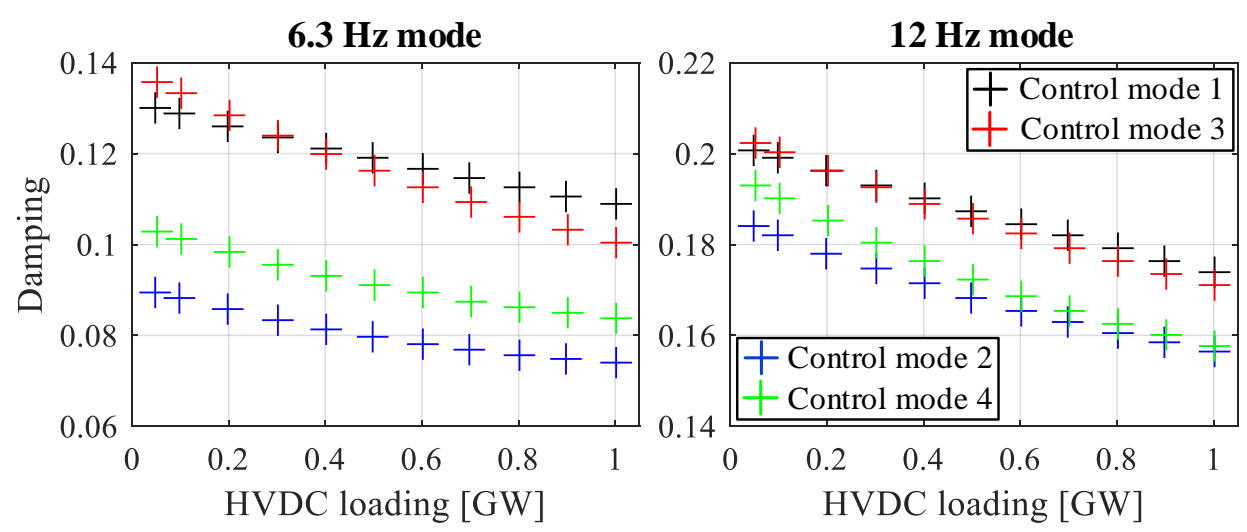

Fig. 5. Torsional damping for the change of the HVDC loading. French SCR is set to 3.

Further studies also show that the impact of the English grid is negligible, and therefore decreasing the English grid strength will not change the results obtained for different French grid strength. Also, the impact of the French X/R ratio and the distance between the HVDC and the generator is minor - damping changes less than 0.01 within the defined parameter range - so this is not exhibited. These figures also show that $12 \mathrm{~Hz}$ mode has much better damping and it has not been possible to excite $12 \mathrm{~Hz}$ instability in our studies.

\subsubsection{Impact of generator reactive power}

The results of the stability analysis show that the generator reactive power may have a notable impact on the torsional damping and this is exhibited in Fig. 6. The operating conditions are kept the same as in the previous section. Only the generator active power is set to $950 \mathrm{MW}$ to enable changing reactive power in the full range from Table 6 . As can be seen from the figure, increasing exported reactive power (positive values) deteriorates torsional damping for AC voltage control on MMC (it can change up to 0.03). However, the damping does not change much for reactive power control on MMC. This indicates that the damping is in fact sensitive to the MMC reactive power which changes as a results of the change of generator reactive power. This is explored next. 

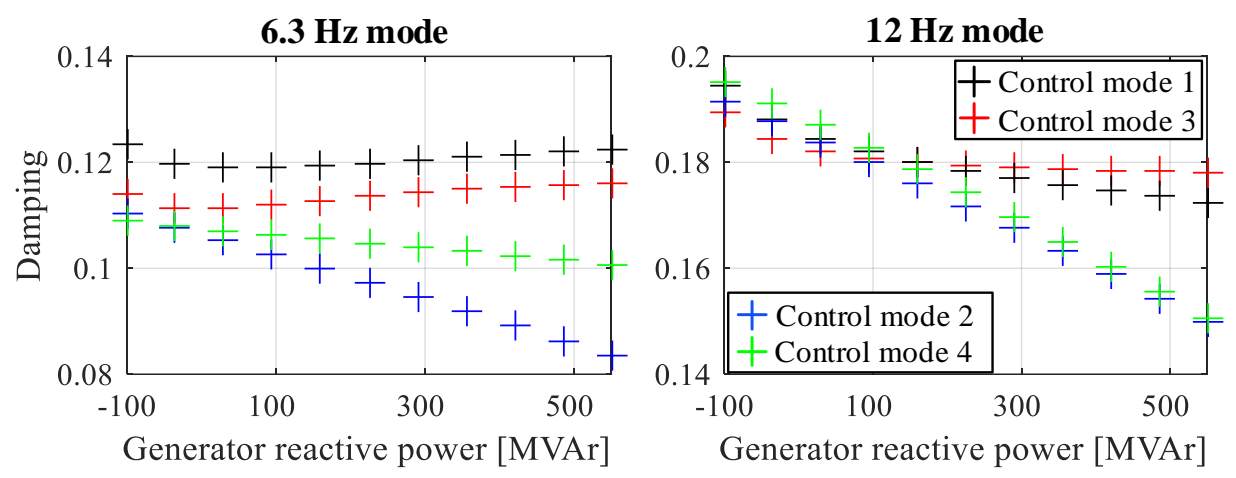

Fig. 6. Torsional damping for the change of the generator reactive power

\subsubsection{Impact of MMC reactive power and AC voltage}

This section investigates the impact of the French MMC reactive power for Control mode 1 and 3, and the impact of the PCC voltage for Control mode 2 and 4. The operating conditions are kept the same as in the previous sections. The generator is delivering rated power with constant reactive power - 0.95 power factor. For MMC in reactive power control, the HVCD loading is set to $900 \mathrm{MW}$ to enable reactive power change in the full range from Table 6. Fig. 7 shows the obtained results. It is seen that high negative (imported) reactive power deteriorates damping notably. The figure also shows that reducing PCC voltage deteriorates damping. The reason for this is that reducing PCC voltage is achieved by increasing imported MMC reactive power. This confirms the assumption from the previous section that the torsional damping is sensitive to the MMC reactive power. Furthermore, the damping is more sensitive as the French AC grid strength is decreasing and the HVDC loading is increasing. Although lower HVDC loading enables higher values of imported reactive power which may further decrease torsional damping. 

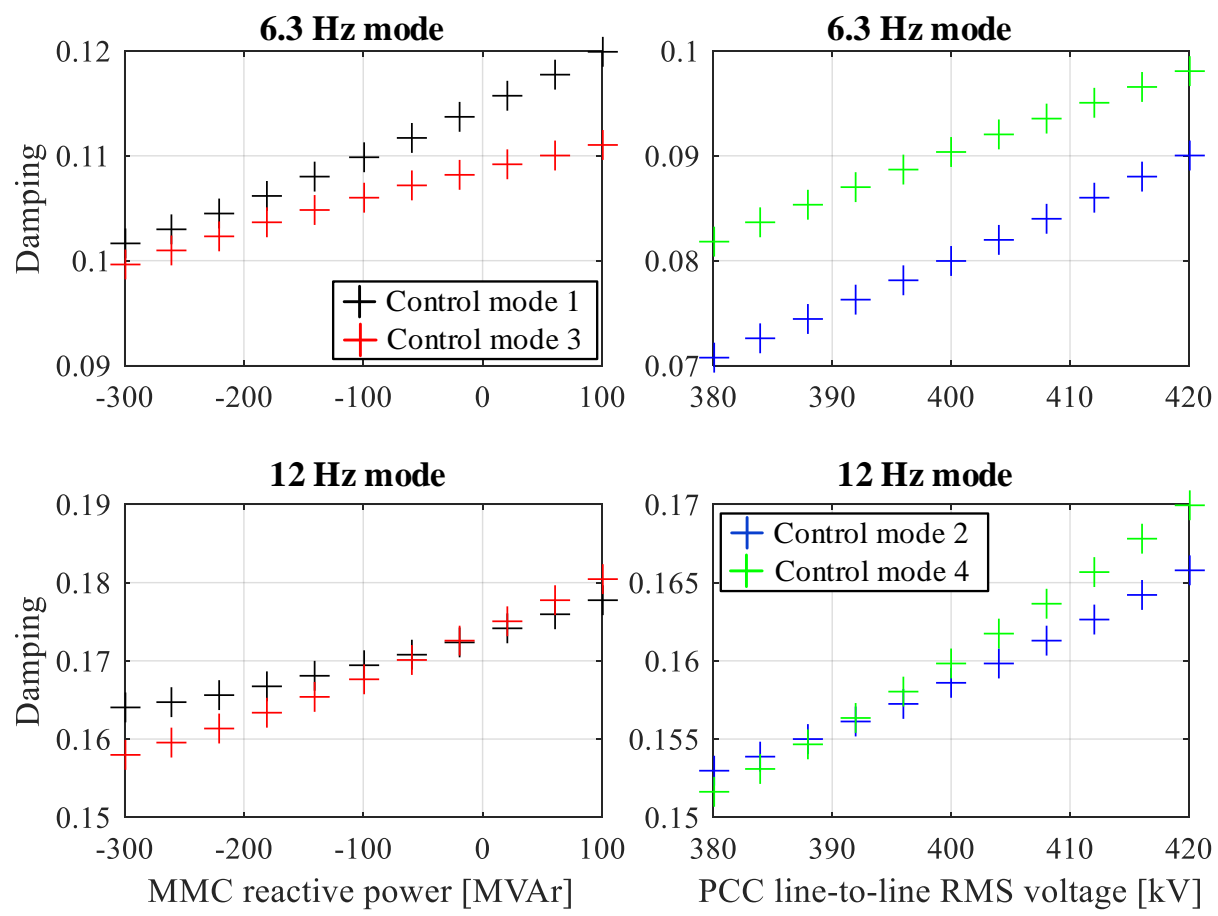

Fig. 7. Torsional damping for the change of the French MMC reactive power (left column) and French PCC voltage (right column).

\subsubsection{Impact of HVDC control}

This section investigates the impact of the HVDC controller gains including PLL. The operating condition remain the same as in the previous sections (generator and HVDC are delivering rated power; French SCR is set to 3). The obtained results show that changing DQ current controller and active power controller gains, within the defined range in Appendix, does not impact torsional damping significantly. The change is less than 0.01 in all cases and so this is not exhibited. It is to be noted that increasing DQ current controller integral gain improves damping while increasing active power controller integral gain deteriorates damping. In case of reactive power controller, increasing integral gain improves damping and this is displayed in Fig. 8. The figure also shows the impact of the $\mathrm{AC}$ voltage controller integral gain which is more significant. One of the reason for this is that a wider range of this gain is considered. 
The study also shows that the $6.3 \mathrm{~Hz}$ mode is sensitive to the change of the AC voltage droop gain. Increasing the gain within the defined limits can improve damping up to 0.01 .
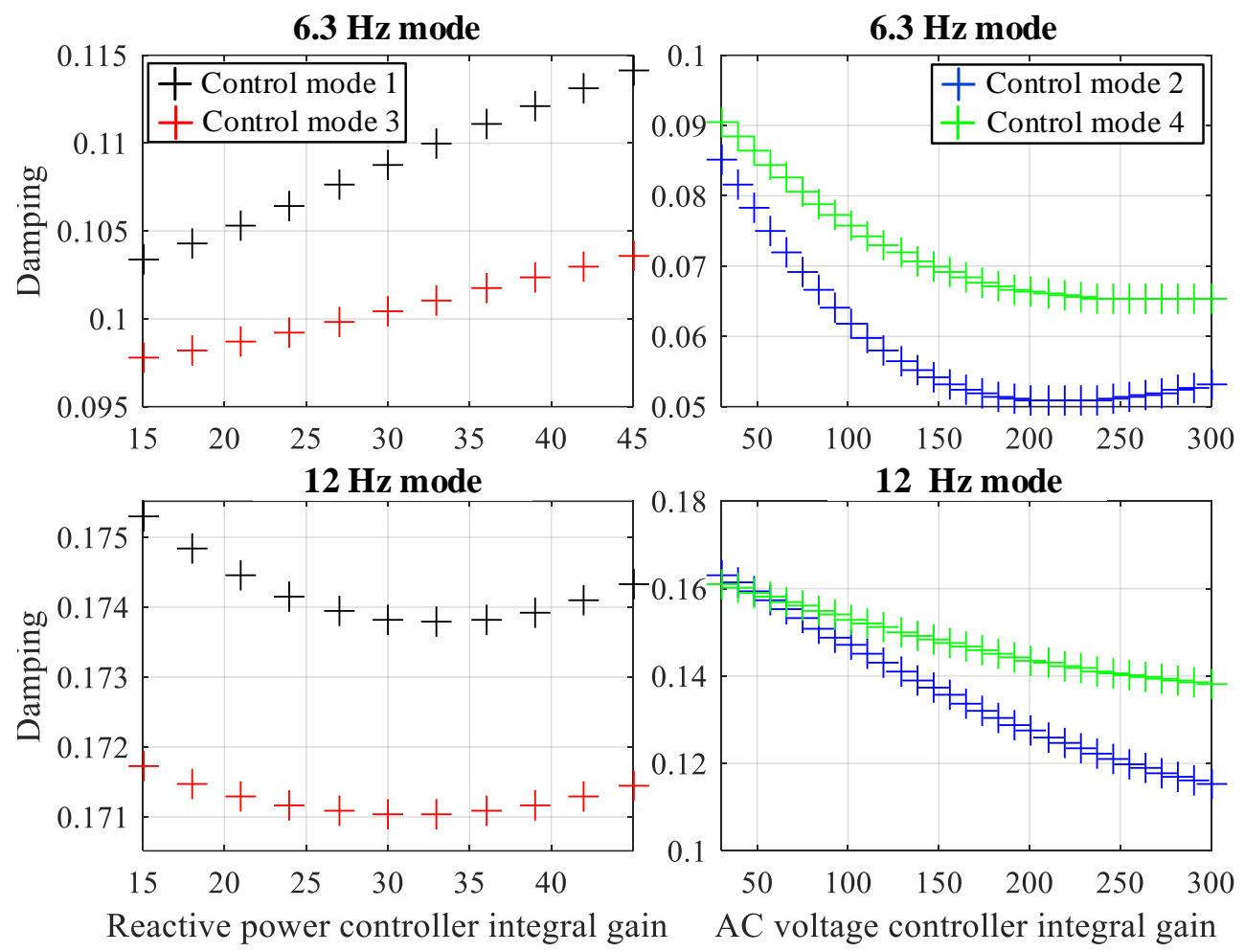

Fig. 8. Torsional damping for the change of the reactive power controller integral gain (left) and the AC voltage controller integral gain (right column).

Fig. 9 shows obtained torsional damping for the change of the French SCR and for two different PLL settings - upper and lower limits from Table 4 in Appendix. The displayed results are obtained for Control mode 2, however, the results are similar for the other control modes. As can be seen from the figure, increasing PLL gains improves damping. Damping is more improved as the grid strength is reducing and also, damping is more improved for the $6.3 \mathrm{~Hz}$ mode. This shows that choosing PLL gains has a significant effect on SSTI particularly for weak grid connections when the risk of adverse interactions is high. This finding also agrees well with the stability of the isolated VSC HVDC systems (the generator is disconnected) [30][31]. Namely, the literature indicates practically no 
stability issues when adopting higher PLL gains for weak AC grid connections on the rectifier side. The case of the weak AC grid on the inverter side is analyzed later on.

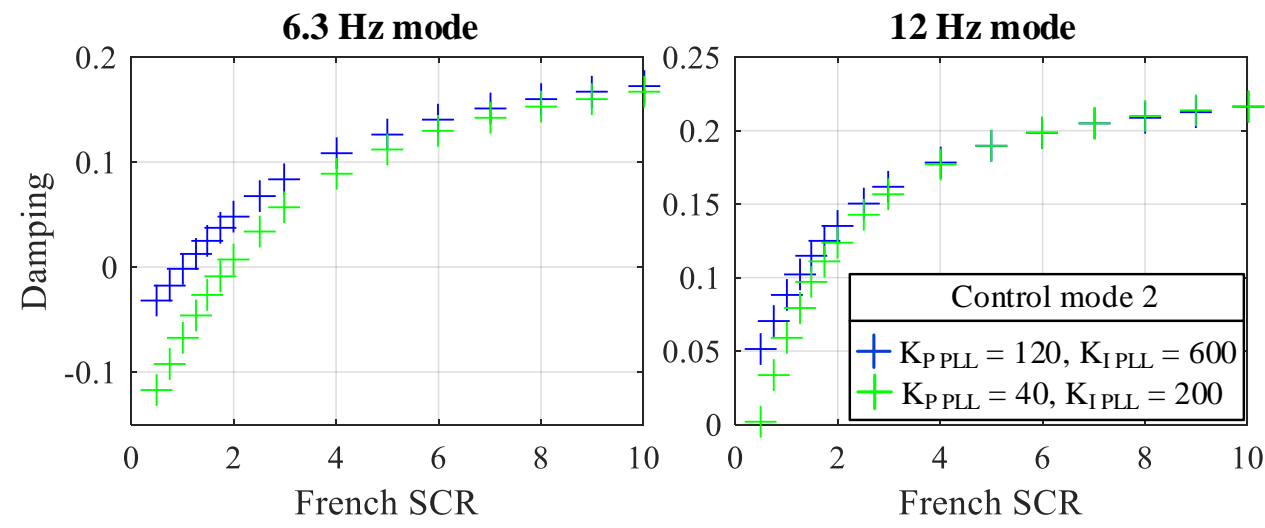

Fig. 9. Torsional damping for the change of the French SCR and for two PLL gain settings.

\subsubsection{Participation factors}

It is shown that the HVDC can destabilize the $6.3 \mathrm{~Hz}$ torsional mode and this section investigates participation factors for the unstable mode. Participations factors are a measure of the relative participation of the state variables in the eigenvalues - torsional mode in this case - and are used here to indicate the cause of SSTI. They are normalized here by dividing with the value for the maximum participation for the eigenvalue. The participation factor of the k-th state in the eigenvalue is calculated as the sensitivity of that eigenvalue to the diagonal element $\mathrm{a}_{\mathrm{kk}}$ of the state space matrix [1]. Table 2 shows obtained dominant participation factors. As can be seen, the angles of the generator shaft masses have the highest participation which is expected. French MMC control has the next highest participation, namely the active power controller, the AC voltage controller and PLL. Similar results are obtained for the HVDC in reactive power control mode in which case, reactive power controller has high participation instead of the AC voltage controller and reactive power instead of the PCC voltage measurement. In case the active power controller 
is on the inverter, for Control mode 3 and 4 , it still has dominant participation and all this indicates that the main cause of SSTI is the control of the HVDC power transfer. The table also reveals that the MMC feedback states have a noticeable participation which means that they could be used as feedback for the development of the supplementary SSTI damping controller on HVDC.

\begin{tabular}{|l|c|l|c|c|c|}
\hline \multicolumn{2}{|c|}{ Generator } & \multicolumn{2}{c|}{ French MMC } & \multicolumn{2}{c|}{ French AC grid } \\
\hline \multicolumn{1}{|c|}{ Model states } & P.F. [\%] & \multicolumn{1}{c|}{ Model states } & P.F. [\%] & Model states & P.F. [\%] \\
\hline Generator speed & 62.77 & PLL output & 0.8015 & Q-axis current & 0.11 \\
\hline Generator angle & 62.77 & AC voltage control output & 0.4523 & D-axis current & 0.0817 \\
\hline LP turbine B speed & 23.72 & Active power control output & 0.4209 & & \\
\hline LP turbine B angle & 23.72 & PLL integrator & 0.1 & & \\
\hline LP turbine A speed & 100 & Q-axis voltage & 0.0993 & & \\
\hline LP turbine A angle & 100 & D-axis voltage & 0.0987 & & \\
\hline HP turbine speed & 17.87 & Q-axis current & 0.023 & & \\
\hline HP turbine angle & 17.87 & PCC voltage & 0.0145 & & \\
\hline & & Active power & 0.0135 & & \\
\hline & & D-axis current & 0.0018 & & \\
\hline
\end{tabular}

Table 2. Participation factors for the unstable $6.3 \mathrm{~Hz}$ torsional mode

\subsection{HVDC importing power from England to France}

\subsubsection{Impact of operating conditions}

This section investigates the risk of the SSTI in case of the HVDC importing power from England to France, which has not been considered in reported studies. The results show that the HVDC contributes positively to the torsional damping (or very small negative contribution) for a wide range of operating conditions, for all the control modes from Table 1 and for the basic HVDC controller setting.

\subsubsection{Impact of HVDC control}

Analysis of the HVDC controller gains shows that the HVDC can reduce damping of only the $6.3 \mathrm{~Hz}$ mode and only for high AC voltage controller integral gain - the higher the gain the more detrimental the impact. Adopting higher values may be required to maintain 
fast $\mathrm{AC}$ voltage step response for strong AC grids. For example, if SCR is 10, basic gain value (60) gives settling time of a few seconds, while 5 times increased gain (value of 300) gives settling time below 0.2 s. Considering gain of 300, the damping is displayed in Fig. 10 - left graph.

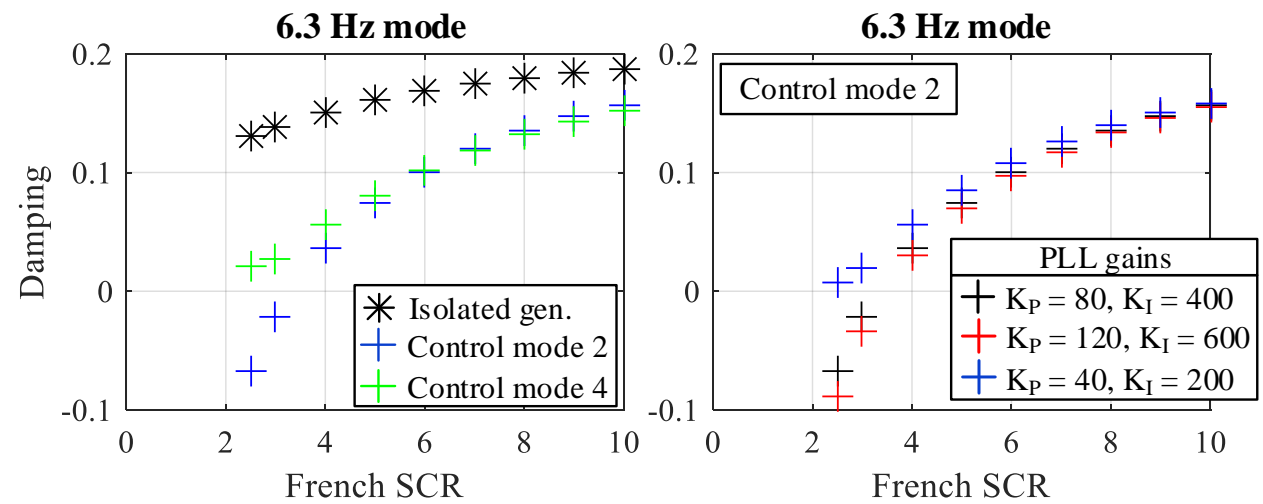

Fig. 10. Damping of the $6.3 \mathrm{~Hz}$ mode for the change of the French SCR and different PLL gains. AC voltage controller integral gain is increased to 300 .

As can be seen, HVDC reduces damping compared to the case of isolated generator and it can even destabilize the mode for the SCR below 3 and for Control mode 2. Control mode 4 shows slightly less detrimental impact. The figure also shows the impact of PLL gains (right graph) and it can be seen that reducing PLL gains improves the damping. It is seen that low inverter PLL gains can even stabilize the $6.3 \mathrm{~Hz}$ mode for all the grid strengths. This finding agrees well with the literature on stability issues of isolated VSC based HVDC systems (generator is disconnected) [29][30][31] which indicates that reducing PLL gains may improve stability margins when the inverter is connected to a weak AC grid.

Furthermore, this is opposite to the results obtained for the HVDC exporting power from France in which case increasing PLL gains reduces the risk of SSTI. This means that adopting different PLL gains on rectifier and inverter could be beneficial for mitigating the risk of SSTI and also improving overall stability margins. Impact of simultaneously 
increased PLL gains on the rectifier and reduced PLL gains on the inverter shows similar benefits on SSTI as shown in Fig. 9 and Fig. 10. The effectiveness of such setting depends on the mechanical torsional damping, the AC grid strengths and the control settings.

\section{Time domain verification}

All the conclusions from the eigenvalue analysis are confirmed by performing simulations on the detailed EMTP model for small signal inputs and this sections shows some of the simulation plots. The modelling of the MMC HVDC in EMTP was formulated by the CIGRE Working Group B4.57 [21] for the purpose of analyzing behavior of HVDC grids and their interactions with the AC systems. Fig 11 shows the EMTP generator-rotor speed response for the active power step on HVDC and for two different PLL settings.

French SCR is set to 1.5 which is a very weak AC grid but expected is some cases [28].

The HVDC is exporting rated power from France to England and the generator is also at rated power. Also the HVDC is in Control mode 2. As can be seen from the figure, for low PLL gains the response shows growing oscillations at the frequency of the $6.3 \mathrm{~Hz}$ mode while for higher PLL gains the oscillations are poorly damped. This confirms that the HVDC can destabilize the $6.3 \mathrm{~Hz}$ mode and that the impact of PLL is of significance.

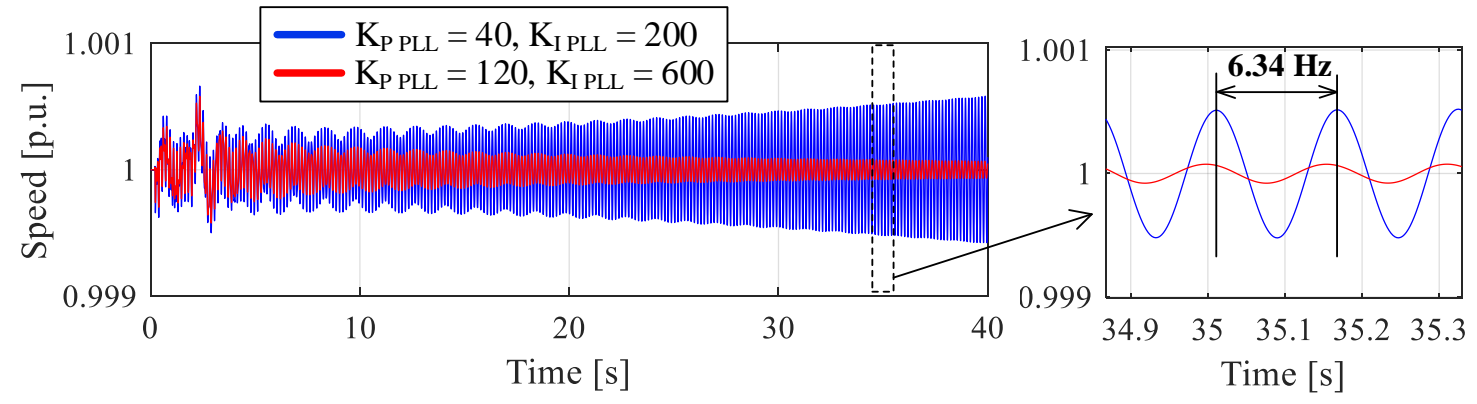

Fig 11. EMTP response of the generator-rotor speed for active power step on HVDC at $2 \mathrm{~s}$. HVDC is exporting rated power from France to England and French SCR is 1.5. 
Fig 12 shows the EMTP responses when the HVDC is importing 0.25 p.u. power from England. The AC voltage controller gain is increased to 150. As can be seen, the figure confirms that the HVDC can destabilize the $6.3 \mathrm{~Hz}$ mode when the power is imported to the generator side and the AC voltage controller gain is high. It also shows the opposite effect of the PLL gains compared to the case of the HVDC power exported from France.

Further EMTP studies for large signal disturbances also show that PLL has similar impact on stability.

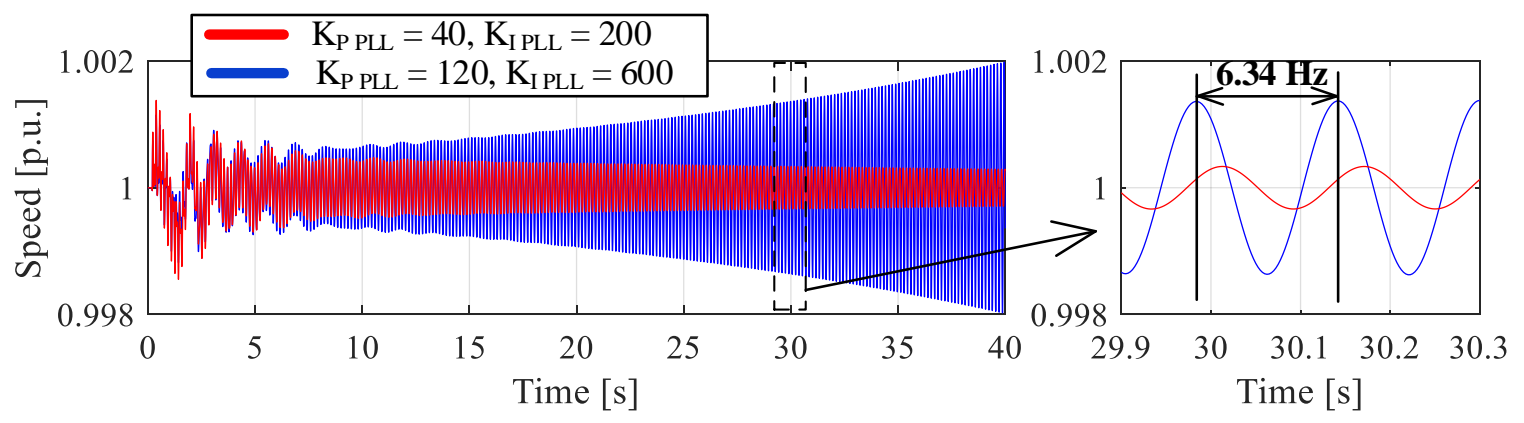

Fig 12. EMTP response of the generator-rotor speed for active power step on HVDC at $2 \mathrm{~s}$. HVDC is importing 0.25 p.u. power from England to France and French SCR is 1.5. AC voltage $\mathrm{K}_{\mathrm{I}}$ is set to 150 .

\section{Conclusions}

The paper investigated the stability of the Eleclink 1GW MMC HVDC coupled with the

1.12GW Gravelines generator in subsynchronous domain. The main conclusions are:

- MMC HVDC may notably deteriorate damping of low frequency torsional modes when the rectifier is connected close to the turbine-generator. Instability is possible for very low SCR. This is contrary to the results of some studies on the MMC HVDC systems and the two level VSC based systems.

- The worst case-scenario is when the generator and HVDC deliver their rated power for low French SCR. 
- Participation factors indicate that the control of the HVDC power transfer in the direction from the generator side is the main cause of the SSTI.

- PLL has a high impact on SSTI. Increasing PLL gains improves torsional damping for weak grid connections and this could be a practical method for SSTI mitigation.

- In case the HVDC is importing power from the English grid, it can deteriorate the damping of the $6.3 \mathrm{~Hz}$ mode but only for high values of the AC voltage controller gains.

- When importing power from England, reducing PLL gains improves torsional damping.

- Adopting different PLL gains on the rectifier/inverter could be beneficial for the SSTI mitigation depending on the other operating conditions.

- The ongoing study considers the combined effect of IFA 2000 and Eleclink HVDC in generator vicinity.

\section{Appendix. HVDC and generator parameters}

\begin{tabular}{|l|c|l|c|}
\hline \multicolumn{2}{|c|}{ Converter parameters } & \multicolumn{2}{c|}{ Underground DC cable parameters } \\
\hline Power rating $(\mathrm{MW})$ & 1000 & Number of poles per cable & 2 \\
\hline DC voltage $(\mathrm{kV})$ & \pm 320 & Vertical distance from ground level $(\mathrm{m})$ & 1.33 \\
\hline Transf. prim. voltage $(\mathrm{kV})$ & 400 & Horizontal distance between poles $(\mathrm{m})$ & 0.5 \\
\hline Transf. sec. voltage $(\mathrm{kV})$ & 350 & Conductor outside radius $(\mathrm{mm})$ & 32 \\
\hline Transf. reactance $(\mathrm{pu})$ & 0.18 & Sheath inside radius $(\mathrm{mm})$ & 56.9 \\
\hline Transf. resistance $(\mathrm{pu})$ & 0.001 & Sheath outside radius $(\mathrm{mm})$ & 58.2 \\
\hline Arm inductance $(\mathrm{pu})$ & 0.12 & Outer insulation radius $(\mathrm{mm})$ & 63.9 \\
\hline Capacitor energy in submodule $(\mathrm{kJ} / \mathrm{MVA})$ & 40 & Conductor resistivity per length unit $\left(10^{-8} \Omega / \mathrm{m}\right)$ & 1.72 \\
\hline Number of submodules per arm & 400 & Sheath resistivity per length unit $\left(10^{-8} \Omega / \mathrm{m}\right)$ & 2.83 \\
\hline & & Relative permeability & 1 \\
\hline & & Insulator relative permittivity & 2.5 \\
\hline & & Insulator loss factor & 0.0004 \\
\hline
\end{tabular}

Table 3. Eleclink MMC HVDC parameters

\begin{tabular}{|c|c|c|c|}
\hline \multicolumn{2}{|c|}{ Active power controller } & \multicolumn{2}{|c|}{ DC voltage controller } \\
\hline Proportional gain & 0 & Proportional gain & 9.6 \\
\hline Integral gain & $15-45$ (basic value is 30 ) & Integral gain & 294 \\
\hline Feedback filter cut-off freq. & $280 \mathrm{~Hz}$ & Feedback filter cut-off freq. & $141 \mathrm{~Hz}$ \\
\hline \multicolumn{2}{|c|}{ Reactive power controller } & \multicolumn{2}{|c|}{$A C$ voltage controller } \\
\hline Proportional gain & 0 & Proportional gain & 0 \\
\hline Integral gain & $15-45$ (basic value is 30 ) & Integral gain & $30-300$ (basic value is 60 ) \\
\hline Feedback filter cut-off freq. & $280 \mathrm{~Hz}$ & Feedback filter cut-off freq. & \\
\hline \multicolumn{2}{|c|}{ AC voltage droop controller } & \multicolumn{2}{|c|}{ Circulating current suppression controller } \\
\hline \multirow{3}{*}{$\begin{array}{l}\text { Droop slope (p.u. reactive } \\
\text { power/p.u. AC voltage) }\end{array}$} & \multirow{3}{*}{$-9--3$ (basic value is -6 ) } & Proportional gain & 0.8 \\
\hline & & Integral gain & 20 \\
\hline & & Feedback filter cut-off freq. & $2000 \mathrm{~Hz}$ \\
\hline
\end{tabular}




\begin{tabular}{|c|c|c|c|}
\hline \multicolumn{2}{|c|}{$D Q$ current controller } & \multicolumn{2}{|c|}{$P L L$} \\
\hline Proportional gain & 1 & Proportional gain (rad/s/p.u.) & $40-120$ (basic value is 80 ) \\
\hline Integral gain & $50-150$ (basic value is 100 ) & Integral gain ( $\mathrm{rad} / \mathrm{s}^{2} /$ p.u. $)$ & 5 times the proportional gain \\
\hline \multicolumn{3}{|c|}{ Voltage feedforward filter cut-off frequency } & $11 \mathrm{~Hz}$ \\
\hline \multicolumn{3}{|c|}{ Terminal voltage and current feedback filter cut-off frequency } & $2000 \mathrm{~Hz}$ \\
\hline
\end{tabular}

\section{Table 4. Range of HVDC controller gains}

\begin{tabular}{|l|l|l|l|l|l|l|l|l|l|l|}
\hline \multicolumn{5}{|c|}{ Electrical parameters (p.u.) } & \multicolumn{5}{c|}{ Mechanical parameters } \\
\hline $\mathrm{L}_{\mathrm{ad}}$ & $\mathrm{L}_{\mathrm{aq}}$ & $\mathrm{L}_{\mathrm{l}}$ & $\mathrm{L}_{\mathrm{fd}}$ & $\mathrm{L}_{\mathrm{ld}}$ & Turbines/generator & HP & LP A & LP B & GEN \\
\hline 2.3 & 2.3 & 0.27 & 0.1502 & 0.0381 & Inertia H [MWs/MVA] & 0.168 & 1.39 & 1.5 & 0.981 \\
\hline $\mathrm{L}_{\mathrm{lq}}$ & $\mathrm{R}_{\mathrm{fd}}$ & $\mathrm{R}_{1 \mathrm{~d}}$ & $\mathrm{R}_{1 \mathrm{q}}$ & & \multicolumn{2}{|l|}{ Spring constant [pu torque/rad] } & 9.48 & 10.94 & 19.09 & \\
\hline 0.0543 & $9.64 \mathrm{e}-4$ & 0.0098 & 0.0089 & & $\begin{array}{l}\text { Mech. damping [pu torque/pu } \\
\text { speed] }\end{array}$ & 0.2 & 0.4 & 2 & 0.4 \\
\hline
\end{tabular}

Table 5. Gravelines generator electrical and mechanical parameters

\begin{tabular}{|l|l|}
\hline \multicolumn{1}{|c|}{ AC parameter } & \multicolumn{1}{c|}{ Parameter range } \\
\hline AC grid SCR & $0.5-10$ (basic value is 5) \\
\hline AC grid X/R & $5-20$ (basic value is 10) \\
\hline Distance between HVDC and generator & $0-50 \mathrm{~km}$ (basic value is 30) \\
\hline Generator active power & $0-1120 \mathrm{MW}$ \\
\hline Generator reactive power & $-100 \mathrm{MVar}$ (import) $-500 \mathrm{MVAr}$ (export) for 950 MW active power \\
\hline HVDC active power & $-1000 \mathrm{MW}-1000 \mathrm{MW}$ \\
\hline HVDC reactive power & $-300 \mathrm{MVAr}$ (import) $-100 \mathrm{MVAr}$ (export) for 900 MW active power \\
\hline PCC voltage & $380 \mathrm{kV}-420 \mathrm{kV}$ RMS line-to-line \\
\hline
\end{tabular}

Table 6. Range of AC parameters and operating conditions

\section{References}

[1] P. Kundur, "Power System Stability and Control," New York: McGraw-Hill, 1994.

[2] P. M. Anderson, B. L. Agrawal, and J. E. V. Ness, "Subsynchronous resonance in power systems," John Wiley \& Sons, 1999.

[3] K. R. Padiyar, "Analysis of subsynchronous resonance in power systems," Springer Science \& Business Media, 2012.

[4] E. Katz, "Subsynchronous Resonance," Paper presented at the panel discussion on Dynamic Stability in the Western Interconnected Power System, IEEE PES Summer meeting, July 18, 1974.

[5] IEEE Subsynchronous Working Group, "Readers guide to subsynchronous resonance," IEEE Trans. Power Syst., vol. 7, no. 1, pp. 150-157, Feb. 1992.

[6] D. H. R. Suriyaarachchi, U. D. Annakkage, C. Karawita and D. A. Jacobson, “A Procedure to Study Sub-Synchronous Interactions in Wind Integrated Power Systems," IEEE Trans. Power Syst., vol. 28, issue 1, pp. 377 - 384, 2013.

[7] IEEE Subsynchronous Resonance Task Force, "First Benchmark Model for Computer Simulation of Subsynchronous Resonance," IEEE Trans. Power App. Syst., vol. PAS-96, no. 5, pp. 1565-1572, September/October 1977.

[8] IEEE Subsynchronous Resonance Working Group, "Second benchmark model for computer simulation of subsynchronous resonance," IEEE Trans. Power App. Syst., vol. PAS-104, no. 5, May 1985.

[9] M. Bahrman, E. V. Larsen, R. J. Piwko and H. S. Patel, "Experience with HVDC - Turbine-Generator Torsional Interaction at Square Butte,” IEEE Trans. Power App. Syst., vol. PAS-99, issue 3, pp. $966-975,1980$.

[10] P. Bornard, D. Souque and A. Vieilpeau, "Torsional interactions between the Gravelines units and the 2000MW cross-channel DC links: Protection of the turbine-generator units," CIGRE International Conference on Large High Voltage Electric systems, 28 Aug. - 3 Sept. 1988.

[11] C. Karawita, "HVDC interaction studies using small signal stability assessment," Ph.D. dissertation, Univ. Manitoba, Winnipeg, MB, Canada, 2009.

[12] S. Kovacevic, D. Jovcic, O. Despouys and P. Rault, "Eigenvalue study of torsional interactions between Gravelines generator and IFA2000 HVDC," Presented at the 20 th International Symposium on Power Electronics, Ee2019, 23 - 26 Oct. 2019.

[13] S. Dennetiere, H. Saad, Y. Varnay, P. Rault, C. Martin and B. Clerc, "Supporting Energy Transition in Transmission systems," IEEE power \& energy magazine, vol. 17, no. 3, May/June 2019.

[14] Y. Jiang-Hafner, H. Duchen, K. Linden, M. Hyttinen, P.F. de Toledo, T. Tulkiewicz, A.-K. Skytt and H. Bjorklund, "Improvement of subsynchronous torsional damping using VSC HVDC," in Proc. Int. Conf. Power Syst., vol. 2, pp. 998 - 1003, 2002.

[15] L. Harnefors, "Analysis of subsynchronous torsional interaction with power electronic converters," IEEE Trans. Power Syst., vol. 22, no. 1, pp. 305 - 313, Feb. 2007.

[16] J. V. Milanovic and A. Adrees, "Identifying generators at risk of SSR in meshed compensated AC/DC power networks," IEEE Trans. Power Syst., vol. 28, no. 4, pp. 4438 - 4447, Nov. 2013.

[17] N. Prabhu and K. R. Padiyar, "Investigation of subsynchronous resonance with VSC-based HVDC transmission systems," IEEE Trans. Power Del., vol. 24, no. 1, pp. 433 - 440, Jan. 2009. 
[18] D. Sun, X. Xie, Y. Liu, K. Wang and M. Ye, "Investigation of SSTI Between Practical MMC-based VSC-HVDC and Adjacent Turbogenerators through Modal Signal Injection Test," IEEE Trans. Power Del., vol. 32, issue 6, pp. 2432 - 2441, 2017.

[19] W. Du, Q. Fu and H. Wang, "Subsynchronous Oscillations Caused by Open-Loop Modal Coupling Between VSC-Based HVDC Line and Power System," IEEE Trans. Power Sys., vol. 33, issue 4, pp. 3664 - 3677, 2018.

[20] D. Jovcic, N. Pahalawaththa and M. Zavahir, "Small signal analysis of HVDC-HVAC interactions," in IEEE Trans. Power Del., vol. 14, no. 2, pp. 525 - 530, April 1999.

[21] CIGRE Working Group B4.57, "Guide for the Development of Models for HVDC Converters in a HVDC Grid," Dec. 2014.

[22] A. Jamshidifar and D. Jovcic, "Small Signal Dynamic DQ Model of Modular Multilevel Converter for System Studies," IEEE Trans. Power Del., vol 31, issue 1, pp 191-199, Feb. 2016.

[23] S. Kovacevic, D. Jovcic, P. Rault and A. Schwob, "Small signal state space model of the frequency-dependent DC cable based on direct vector fitting," Presented at the $15^{\text {th }}$ IET international conference on AC and DC Power Transmission, ACDC 2019, Feb. 2019.

[24] J. Beerten, S. D'Arco and J. A. Suul, "Frequency-dependent cable modelling for small-signal stability analysis of VSC-HVDC systems," IET Gen., Trans. \& Dist., vol. 10, issue 6, pp. 1370 - 1381, 2016.

[25] P. H. Adam and Z. Yao, "Validation of digital simulation for studies of torsional interaction between a turbo-generator and an HVDC link," Electricite de France (EDF), France, 1991.

[26] IEEE Recommended Practice for Excitation System Models for Power System Stability Studies, IEEE Standard 421.5-2016.

[27] "Dynamic Models for Turbine-Governors in Power System Studies," Technical report PES-TR1, IEEE Power \& Energy Society, Jan. 2013.

[28] D Jovcic "High Voltage Direct Current Transmission: Converters Systems and DC Grids", 2nd edition Wiley, 2019.

[29] J. Z. Zhou, H. Ding, S. Fan, Y. Zhang and A. M. Gole, "Impact of Short-Circuit Ratio and Phase-Locked-Loop Parameters on the Small-Signal Behavior of a VSC-HVDC Converter," IEEE Trans. Power Del., vol. 29, issue 5, pp. 2287 - $2296,2014$.

[30] L. Harnefors, M. Bongiorno, S. Lundberg, "Input-Admittance Calculation and Shaping for Controlled Voltage-Source Converters," IEEE Trans. Ind. Electron, vol. 54, no. 6, Dec. 2007.

[31] Y. Wang, C. Zhao, C. Guo, “Comparison study of small-signal stability of MMC-HVDC system in different control modes,” Int. J. Elec. Power, vol. 111, pp. 425-435, Oct. 2019.

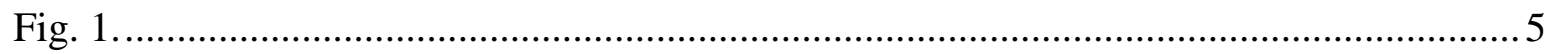

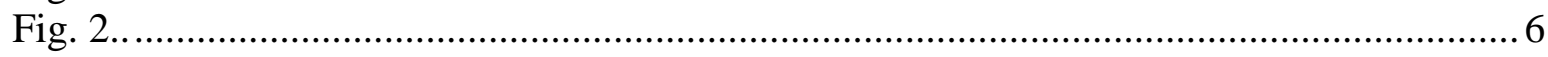

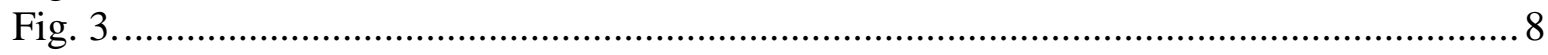

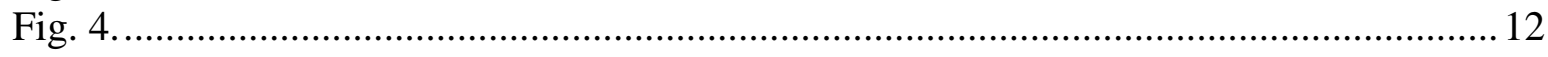

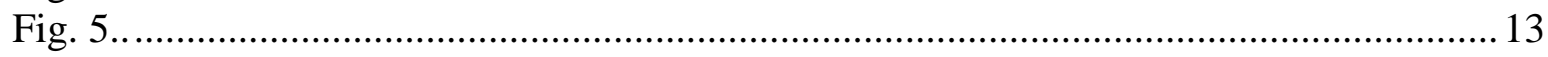

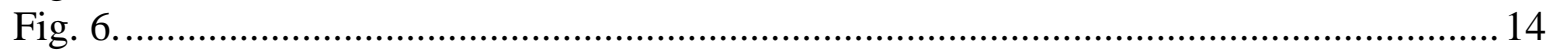

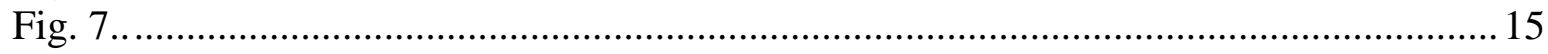

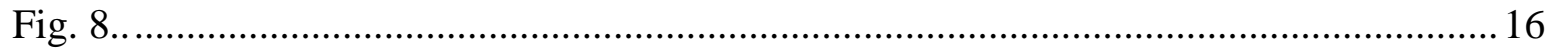

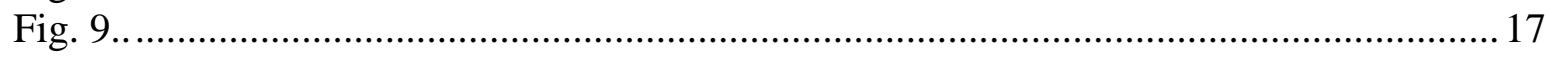

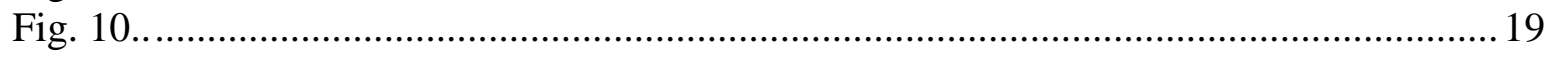

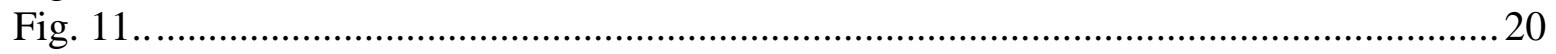

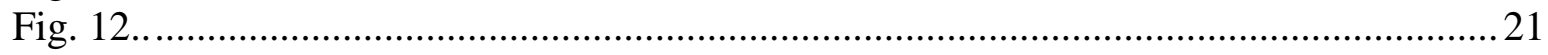

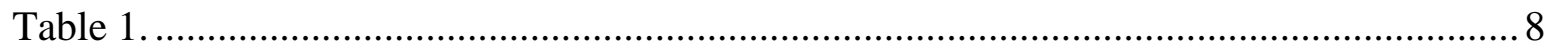




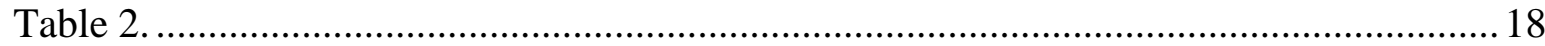

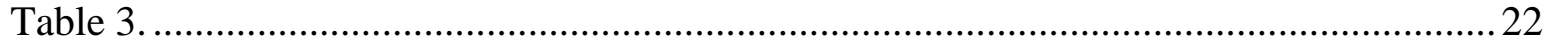

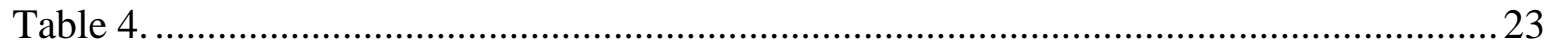

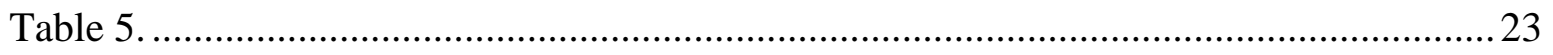

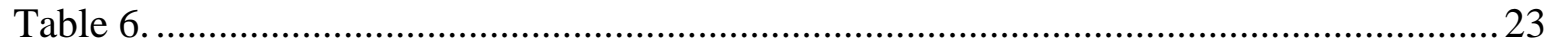

